Characterize and Model Final Waste Formulations and Off-Gas Solids from Thermal Treatment Processes

FY-98 Final Report for LDRD \#2349

G. F. Kessinger

L. O. Nelson

J. D. Grandy

L. D. Zuck

P. C. Kong

G. L. Anderson

August 1999 


\title{
Characterize and Model Final Waste Formulations and Off-Gas Solids from Thermal Treatment Processes FY-98 Final Report for LDRD \#2349
}

\author{
G. F. Kessinger \\ L. O. Nelson \\ J. D. Grandy \\ L. D. Zuck \\ P. C. Kong \\ G. L. Anderson
}

Published August 1999

Idaho National Engineering and Environmental Laboratory Idaho Falls, Idaho 83415

Prepared for the

U.S. Department of Energy

Under DOE Idaho Operations Office

Contract DE-AC07-99ID13727 


\begin{abstract}
The purpose of LDRD \#2349, Characterize and Model Final Waste

Formulations and Offgas Solids from Thermal Treatment Processes, was to develop a set of tools that would allow the user to, based on the chemical composition of a waste stream to be immobilized, predict the durability (leach behavior) of the final waste form and the phase assemblages present in the final waste form. The objectives of the project were:

- investigation, testing and selection of thermochemical code

- development of auxiliary thermochemical database

- synthesis of materials for leach testing

- collection of leach data

- using leach data for leach model development

- thermochemical modeling

The progress toward completion of these objectives and a discussion of work that needs to be completed to arrive at a logical finishing point for this project will be presented.
\end{abstract}




\section{CONTENTS}

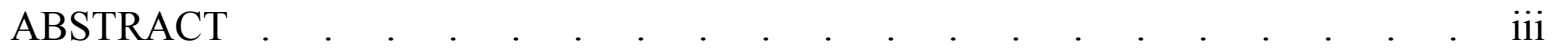

INTRODUCTION

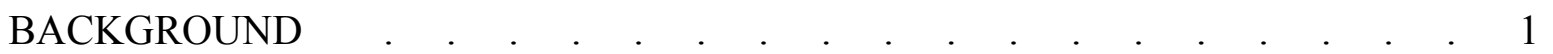

INVESTIGATION, TESTING AND SELECTION

OF THERMOCHEMICAL CODE . . . . . . . . . . . . . 3

DEVELOPMENT OF AUXILIARY THERMOCHEMICAL DATABASE. . . . 4

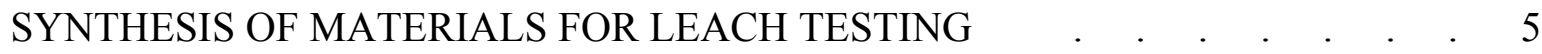

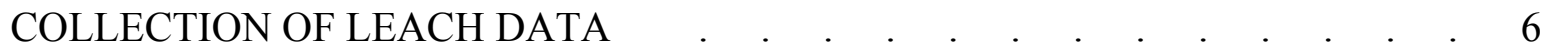

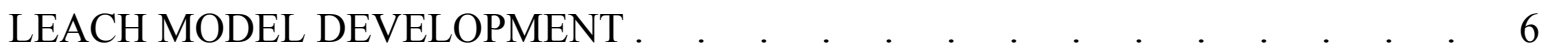

Thermodynamic Approach . . . . . . . . . . . . . . . 6

Kinetic Approach . . . . . . . . . . . . . . . . . . . . .

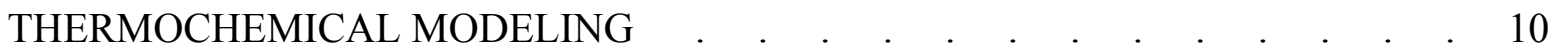

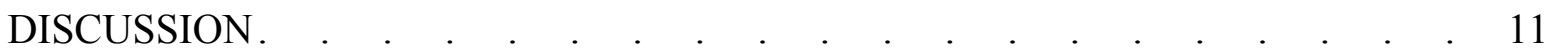

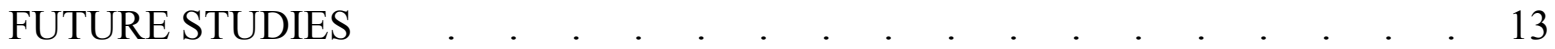

Thermodynamic Modeling . . . . . . . . . . . . . . . . . . 13

Leach Modeling . . . . . . . . . . . . . . . . . . 13

Appendix A: Basic Mass Transfer Leaching Theory ․ . . . . . . . . 14

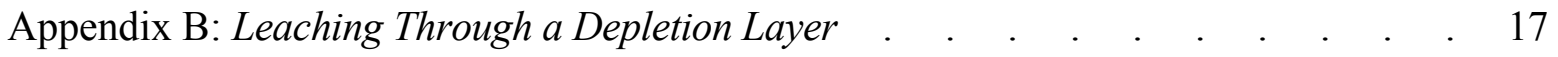

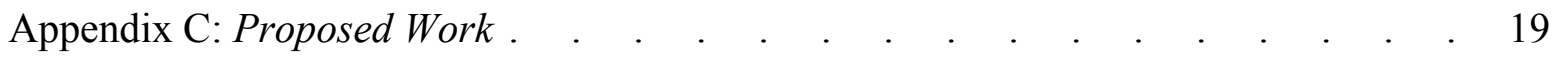

FIGURES

Figure 1- Spinosa Data $\quad$. $\quad . \quad$.

\section{TABLES}

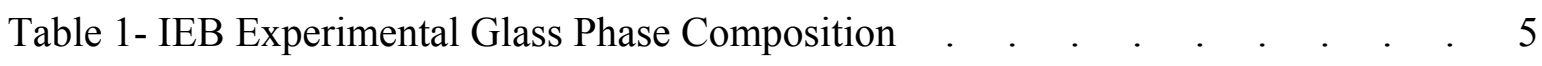

Table 2- Chemical composition of 70 w/o Transuranic Storage Area

Wastes Blended with 30 w/o INEEL Soil ․ . . . . . . . . . 11 


\section{INTRODUCTION}

The purpose of LDRD \#2349, Characterize and Model Final Waste Formulations and Offgas Solids from Thermal Treatment Processes, was to develop a set of tools that would allow the user to, based on the chemical composition of a waste stream to be immobilized, predict the durability (leach behavior) of the final waste form and the phase assemblages present in the final waste form. The objectives of the project can be conveniently partitioned into the following areas/activities:

- investigation, testing and selection of thermochemical code

- development of auxiliary thermochemical database

- synthesis of materials for leach testing

- collection of leach data

- using leach data for leach model development

- thermochemical modeling

Some background will be discussed below, followed by the topics listed. Lastly, a discussion of work that needs to be completed to arrive at a logical finishing point for this project will be completed.

\section{BACKGROUND}

The nuclear fuel cycle was completed in the early 1950's with the construction of the Idaho Chemical Processing Plant at the INEL. This plant was used to recover unfissioned uranium from irradiated reactor fuels. The raffinates from the aqueous dissolution/extraction process were initially stored, as acidic wastes, in underground tanks. Since these wastes were not neutralized (as was the case at Hanford and Savannah River), it was possible to consider a variety of waste processing alternatives. Immobilization of liquid high level radioactive wastes (HLW) at the INEEL has been underway since construction and cold testing of the demonstration waste calcination facility (WCF) at ICPP (now INTEC) was completed in $1962{ }^{1}$

Not long after WCF was completed, development work was initiated on a final waste form for calcined wastes. In the 1960's and 1970's, waste form development was directed toward the development of glass waste forms. Initially, a phosphate glass form was developed; later borosilicate glass forms were investigated. Finally, in the 1980's, glassceramic forms were investigated; that development work was initiated because of the desire for volume reduction. Glass-ceramics can accommodate up to 70 weight percent (w/o) calcined waste as compared to the limit of about $30 \mathrm{w} / \mathrm{o}$ for glass waste forms. The increased waste loading, coupled with the increased density of the glass-ceramic, about $50 \%$ more dense than glass, would result in a considerable smaller volume of waste. Lastly, glassceramic waste forms are generally more durable than glass waste forms. The drawback to this waste form, as compared to glass, is processing difficulty; glass-ceramics are formed by hot isostatic pressing of a mixture of waste and additives, which is a more complex process than glass melting in a Joule heated melter.

The chemistry of glass-ceramic waste forms developed for calcine immobilization is governed by the chemical reactions of the calcine and additives. The calcine, depending on the type of fuel processed, can contain large amounts of alumina, zirconia and calcium

\footnotetext{
${ }^{1}$ D.A. Knecht, M.D. Staiger, J.D. Christian, C.L. Bendixsen, G.W. Hogg and J.R. Berreth, "Historical Fuel Processing and HLW Management in Idaho," Radwaste, 4(3), 35, 1997.
} 
fluoride; the additives include: $\mathrm{SiO}_{2}, \mathrm{Na}_{2} \mathrm{O}, \mathrm{B}_{2} \mathrm{O}_{3}, \mathrm{CuO}, \mathrm{Li}_{2} \mathrm{O}, \mathrm{TiO}_{2}$ and $\mathrm{Y}_{2} \mathrm{O}_{3}$. The additives are tailored to the waste composition to arrive at a chemical composition that will allow durable phases to be formed.

Concurrent with the development of glass-ceramic waste forms at INTEC were numerous programs to develop waste forms for transuranic (TRU) wastes. The Radioactive Waste Management Complex (RWMC) at the INEEL is a "facility" where TRU wastes are stored. Some of this material was buried in shallow trenches (also known as "pits"), some of it is stored above ground on asphalt pads in boxes and barrels, and some is stored in "dry wells. In addition, some of this waste is mixed (both RCRA hazardous and radioactive) waste. In many cases, the wastes are not particularly well characterized. The wastes in Pit 9 and those to be immobilized at the Advanced Mixed Waste Treatment Facility (AMWTF) are among the wastes stored at RWMC.

Waste form development for the immobilization of these wastes has produced the iron-enriched basalt (IEB) and IEB4 waste forms. The IEB waste forms are the results of an ingenious approach. A thermal treatment process in which the contaminated soil in which waste is buried is used as a "solvent" for the radioactive and hazardous components in the waste is used to produce a multi-phasic waste form that is similar to the naturally-occurring basaltic rock in the region, except that iron is substituted for some of the magnesium and aluminum (thus the name iron-enriched basalt). The IEB4 waste form is a modification of the IEB waste form that incorporates group IVB elements $\mathrm{Zr}$ and $\mathrm{Ti}$ into the waste form to facilitate the formation of zirconolite $\left(\mathrm{CaZrTi}_{2} \mathrm{O}_{7}\right)$, which is a known host phase for actinides.

During the development of the glass-ceramic waste forms at INTEC and the IEB waste forms for RWMC, attempts were made to use predictive tools to allow developers to model the high temperature chemistry of these complex systems. These attempts met with some success, but nevertheless were inadequate. The inadequacies were related to limitations in the computational codes, such as the inability of the codes to minimize the free energy of systems with numerous elements and hundreds of possible phases, and the difficulty of building solution models to address the molten phases encountered during thermal processing of these complex chemical systems.

During the years since these initial modeling efforts were undertaken, the computational power of personal computers (PCs) has increased considerably (for example the PC being used to compose this report can be used to thermochemically model a chemical system of 20 elements in which hundreds of vapor species and pure condensed phases and numerous non-ideal liquid/molten solutions are considered, and it will solve the problem faster than a PC could solve a system with less than 100 species, and a single ideal liquid phase only 10 years ago). With the new, more powerful models and computers, it is possible to address complex chemical systems with relative ease.

The performance of waste forms is the way in which their "desirability" is measured. When a waste form reaches its "final" destination, it is expected, with some degree of certainty, that the waste form will not degrade and release its constituent parts to the ecosystem. Tests to measure the "release rates" of materials have been developed. These tests, referred to as leach tests, generally involve subjecting the candidate waste form to water, in either static or flowing system, for long periods of time under well defined conditions. Waste forms that are resistant to leaching (with release rates judged by a regulator to be below concern) of their chemical components (either as compounds or as elements) by $\mathrm{H}_{2} \mathrm{O}$ are desirable; those that are not chemically durable are undesirable. 
Prediction of the performance of waste forms is a difficult undertaking. The complexity is based on numerous factors. Those of primary interest include knowledge of the final state and condition of disposition, chemical composition, phase composition, and the availability of experimental data. Repository conditions are unknown, as no repository has been licensed and built. In addition, the climatic and geochemical conditions at the time of repository siting and construction may or may not be the conditions 100,500 , or 1000 years later.

The chemical and phase composition of waste forms are probably the most important factors in waste form performance. The behavior of materials in which the constituents are at chemical equilibrium, with regard to transformations to other phases, may be predicted with more certainty than those not in an equilibrium state. This does not, however, mean that all materials must necessarily be in their "most stable state" with regard to phase transformations. For example, glasses are, by definition, metastable phases, but obsidian glasses have survived for long periods of time on a geologic scale without undergoing devitrification to form crystalline phases. The generation and availability of experimental data is closely connected to the phase behavior and chemical compassion of the waste forms; however, the lack of data can be addressed by performing experiments.

An ideal way to address waste form development would be to have the tools available to predict the chemical durability of a waste form based on the chemical composition of the waste and additives used to produce the waste form. The goal of this project was to lay the groundwork for the development of these tools.

\section{INVESTIGATION, TESTING AND SELECTION OF THERMOCHEMICAL CODE}

Numerous thermochemical modeling codes were considered during this project; these included the Geochemical Program Package (GPP), the Facility for the Analysis of Chemical Thermodynamics (FACT) package, IVTHERM, TEQWORKS, STEPSOL, HSC and MELTS. The evaluation of these codes was fairly straight-forward. STEPSOL and MELTS were eliminated from consideration because they had inadequate databases and were not robust enough to perform the calculations of interest. MELTS was eliminated because it had an inadequate database; this code is geared toward geochemical calculations and did not have zirconia included in the database. GPP was eliminated because it had an inadequate database and it was written in an archaic language that required modification prior to use on a PC. The three remaining codes, IVTHERM, HSC and FACT will be discussed in more detail.

Of these three, HSC is the easiest to use. It is visually represented as a spreadsheet and is a Windows menu-driven code. It has a fairly extensive database that includes many mineral-type phases that are of interest for this work. Its weakness is that it lacks robustness. It is limited in the number of species and phases that can be considered during a calculation and it is weak in the area of liquid solutions.

IVTHERM is also a menu-driven code, but it runs in the DOS environment. Its strength is that it is fairly easy to use. Its weaknesses are the database and the inability to address complex solutions.

The FACT Gibbs free energy minimization code, EQUILIB, is also menu-driven, and runs in the DOS environment. Its strengths are the database, the numerous built-in non-ideal solutions available for addressing the chemistry of melts, and the robust computational code. Its shortcoming is that it runs in the DOS environment, which can sometimes make it 
cumbersome to use. This shortcoming will shortly be alleviated, as an upgrade of the code, expected to be release during late 1998, will be Windows-based.

After the review of all of these codes, it was determined that the FACT package ${ }^{2}$ was the best overall choice for the development of the predictive tools for waste form development activities. This package consists of numerous codes that are described below. COMPOUND- The COMPOUND code is used to display the data present in the FACT thermochemical database, FACTBASE. It may also be used to display the data present in the user-generated database, USERBASE.

SOLUTION- This code allows the user to build solution models and save them in the userdefined database. It also allows the user to recall a FACT solution data file for inspection or editing and to copy that solution model into the private solution database.

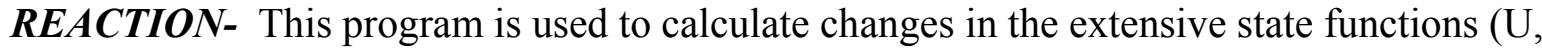
$\mathrm{H}, \mathrm{G}, \mathrm{A}, \mathrm{V}$, and $\mathrm{C}_{\mathrm{p}}$ ) for a species or for a chemical reaction. The code uses data from the FACT database and the user-defined database.

PREDOM- The PREDOM code is used to generate isothermal and non-isothermal predominance diagrams that show the possible phases that are most stable over a specified range of pressures. These plots can be $\log \mathrm{P}$ versus $\log \mathrm{P}$ plots, or can be $\log \mathrm{P}$ versus temperature plots. The data used to generate the plots is abstracted, by the code from the FACT thermochemical database.

$\boldsymbol{E P H}$ - This program is used to produce Pourbaix (E versus $\mathrm{pH}$ ) diagrams for aqueous chemical systems based on user-specified temperatures and species concentrations. The program uses data from both the FACT database and the user-defined database for these calculations.

EQUILIB- This code, which is based on Ericksson's Gibbs free-energy minimization code SOLGASMIX, uses thermochemical data (from the FACT database and/or the user-defined database) and user-inputted chemical composition, choice of phases to be considered, temperature, pressure and final conditions, to determine the chemical equilibrium state of the system under consideration. In addition, the changes in the extensive state variables may also be computed based on the initial and final conditions defined by the user. This code has previously been used at INTEC for waste form work and process development activities. In addition, a report was generated during the verification of the INTEC studies.

\section{DEVELOPMENT OF AUXILIARY THERMOCHEMICAL DATABASE}

Most of the phases of species of interest are included in the FACT thermochemical database. Notable exceptions include zirconolite $\left(\mathrm{CaZrTi}_{2} \mathrm{O}_{7}\right)$ and substituted spinels (such as $\mathrm{FeFe}_{2-\mathrm{x}} \mathrm{Cr}_{\mathrm{x}} \mathrm{O}_{4}$, where $\mathrm{x}<<0.1$ ). For these phases, thermochemical data would need to be estimated or found in the literature. Recent work on waste immobilization of uranium and plutonium addresses this situation for zirconolite. Oxide melt solution calorimetry has been used to determine the thermodynamic quantities required to compute the enthalpy of formation of zirconolite. These data were used to generate $\mathrm{C}_{\mathrm{p}}(\mathrm{T}), \Delta \mathrm{H}^{\mathrm{O}}{ }_{298}$, and $\mathrm{S}_{298}^{\mathrm{O}}$ for zirconolite; these quantities were subsequently used in calculations on RWMC TSA wastes.

Thermodynamic quantities for substituted iron spinels have not been measured; however, this isn't of particular concern because these quantities can be easily estimated

\footnotetext{
${ }^{2}$ C.W. Bale, A.D. Pelton and W.T. Thompson, "FACT 2.1 User's Manual," Ecole Polytechnique de Montreal/Royal Military College, Canada, July 1996 (http://www.crct.polymtl.ca).
} 
from the quantities for the pure components (such as $\mathrm{Fe}_{3} \mathrm{O}_{4}$ and $\mathrm{Cr}_{2} \mathrm{O}_{3}$ ) as these quantities are needed.

\section{SYNTHESIS OF MATERIALS FOR LEACH TESTING}

Due to the need of experimental leach data for leach model development, samples were synthesized for leach testing. The phases that have been identified in IEB simulated waste forms include: glass (of varying composition), plagioclase [anorthite, $\left.(\mathrm{Ca}, \mathrm{Na})(\mathrm{Si}, \mathrm{Al})_{4} \mathrm{O}_{8}\right]$, spinel $\left[\mathrm{Mg}(\mathrm{Al}, \mathrm{Fe})_{2} \mathrm{O}_{4}\right]$, pyroxene [clinopyroxene, $\left.\mathrm{Ca}(\mathrm{Mg}, \mathrm{Fe}, \mathrm{Al}) \mathrm{Si}_{2} \mathrm{O}_{6}\right]$, and hematite. In IEB4 simulated waste forms, additional phases, such as zirconolite, psuedobrookite $\left(\mathrm{Fe}_{2} \mathrm{TiO}_{5}\right)$, titaniferrous magnetite $\left[(\mathrm{Fe}, \mathrm{Ti}) \mathrm{Fe}_{2} \mathrm{O}_{4}\right]$ and zirconia, were also formed due to the addition of $\mathrm{TiO}_{2}$ and $\mathrm{ZrO}_{2}$. To adequately model the leaching of this chemical system would require the completion of a suite of leach tests for each phase of interest. As time and money were not available to perform all of the tests, a few of the more important phases were chosen for initial study. Those were glass, zirconolite, substituted zirconolite, iron spinel and substituted iron spinel; the glass composition is presented in Table 1.

\begin{tabular}{|c|c|}
\hline \multicolumn{2}{|c|}{ Table 1 } \\
IEB Experimental Glass Phase Composition \\
\hline Compound & Percentage/weight percent \\
\hline $\mathrm{Na}_{2} \mathrm{O}$ & 5.0 \\
\hline $\mathrm{MgO}$ & 5.0 \\
\hline $\mathrm{Al}_{2} \mathrm{O}_{3}$ & 10.0 \\
\hline $\mathrm{SiO}_{2}$ & 60.0 \\
\hline $\mathrm{K}_{2} \mathrm{O}$ & 5.0 \\
\hline $\mathrm{CaO}$ & 5.0 \\
\hline $\mathrm{Fe}_{2} \mathrm{O}_{3}$ & 10.0 \\
\hline $\mathrm{Total}$ & 100.0 \\
\hline
\end{tabular}

Glass phase synthesis was according to the method of Callow, Grandy \& $\operatorname{Herzog}^{3}$ and proved to be straightforward. Synthesis of zirconolite, to the contrary, proved to be somewhat difficult. Mixtures of the appropriate metal oxides or carbonates (in the case of calcium, the carbonate) were mixed and heated to temperatures below $1773 \mathrm{~K}$, either as powders or after pressing the material into a pellet. The materials were contained in highfired alumina crucibles. Most of the difficulty in sample synthesis was related to operation of the laboratory muffle furnace. Temperature control was initially difficult, and the first attempts resulted in melted samples (zirconolite melts in the range $1773 \mathrm{~K}-1823 \mathrm{~K}$ ). There were visual indications of erosion of the crucibles at the vapor-liquid/solid interface that suggest the melts reacted with the crucible. The products of these experiments resulted in materials that included aluminates among the phases identified by XRD analyses, which confirmed the visual observations. It was later discovered that one bank of molybdenum silicide heating elements in the furnace was not heating (due to a broken element), so there was a considerable temperature gradient in the furnace. After the problems with the furnace

${ }^{3}$ R.A. Callow, J.D. Grandy and J.D. Herzog, "Iron-Enriched Basalt Waste Form Studies," report no. INEL-96/244, LMITCO, Idaho Falls, ID, 1996. 
were alleviated, it was possible to make two-phase, zirconolite-calcium titanate materials that would be adequate for leach testing. These materials were nearly white in color.

The cerium-substituted zirconolite syntheses were performed in a straightforward fashion. Mixtures were pressed into pellets and heated to temperatures below $1773 \mathrm{~K}$ for times up to many days in duration, during which the samples were removed from the oven, were analyzed, and subsequently homogenized by mortar and pestle prior to resumption of the heating experiment. The products of these experiments were initially (after the early heatings) brownish-purple, but by the end of the multiple heatings were very pale brown in color; the XRD analyses showed two zirconolite phases in addition to calcium titanate. Attempts were made to detect the transition temperature (if one exists) for the zirconolite phase transition, but the experiments were unsuccessful.

Two sources of iron spinel were identified. The first was synthesis from a mixture of ferrous and ferric oxides; the second was magnetite purchased as such. Synthesis proved difficult, as the oxygen potential of the mixture must be closely controlled, least the material be completely oxidized to ferric oxide (as was the case) or reduced to ferrous oxide (if the oxygen potential were too low). Fortunately, the purchased magnetite was adequate for this application. Synthesis of the substituted spinel was not completed due to time and budget constraints.

\section{COLLECTION OF LEACH DATA}

Leach data were collected for two types of samples, glass and zirconolite. The Product Consistency Test (PCT) protocol was used. This is a static leach test in which materials of known surface area are subjected to $\mathrm{H}_{2} \mathrm{O}$ under a defined set of conditions. Leachants are analyzed by inductively-coupled plasma atomic absorption/atomic emission (ICP-AA/AE) to detect the solutes. From these data, the rate of release of material from the leachate is computed. Due to time constraints and instrumental problems in the analytical laboratory, the ICP-AA/AE analyses of the leachates had not yet been analyzed when this report was written.

\section{LEACH MODEL DEVELOPMENT}

Two approaches to modeling leach behavior were embarked upon in the project: (1) the thermodynamic approach and (2) the kinetic approach. The second approach is the more difficult, primarily because of the kinetics approach. It should be noted, however, that the second approach may well be more useful for predicting leach behavior.

Thermodynamic Approach- Development of this approach is complete. The FACT EQUILIB code thermochemical database can be used to compute the chemical equilibria of complex solid-liquid-aqueous-vapor systems. Thermodynamic data for essentially all of the commonly encountered solid, liquid, aqueous, and vapor species are resident in the FACT database. This is the approach that Kosson ${ }^{4}$ has taken to address the leaching behavior of municipal incinerator ash. While Kosson has used a different code, MINTEQA2, a geochemical code for computing the equilibria of heterogeneous systems in which one of the phases is aqueous, the approach is similar to that used with EQUILIB.

\footnotetext{
${ }^{4}$ A.J. Chandler, T.T. Eighmy, J. Hartlen, O. Hjelmar, D.S. Kosson, S.E. Sawell, H.A. van der Sloot and J. Vehlow, "Studies in Environmental Science 67, Municipal Solid Waste Incinerator Residues,” Elsevier Science B.V., Amsterdam, The Netherlands, 607-633, 1997.
} 
MINTEQA2 is the culmination of over a decade of work aimed at modeling the behavior of geochemical systems. It is based on the REDEQL and WATEQ3 codes and is distributed by EPA. It approaches computation of chemical equilibria from the equilibrium constant direction and addresses the aqueous solutions using the Debye-Huckel and Davies equations to compute activity coefficients for aqueous species.

The approaches of MINTEQA2 and EQUILIB should both do an adequate job of addressing the "static" leaching situation. In that situation, the equilibrium condition is the infinite time condition. How close to equilibrium a leachant and leachate are after weeks, days, months or years is a function of a variety of factors which the equilibrium approach cannot address.

Kinetic Approach- The primary purpose of the modeling effort is development of a tool to predict the leaching behavior of the IEB waste form under various conditions that might be found in a repository. IEB is known to form a glassy phase and several crystalline phases as it devitrifies when cooling. Since each of these phases can be expected to have different leaching characteristics, the approach taken in this program is to experimentally determine the leaching characteristics of all the individual phases. The resulting data can then be used in a modeling program to predict the leaching behavior of IEB composed of any possible combination of the individual phases and under a variety of temperature and flow conditions.

A finite element model is being developed to represent the leaching behavior of a monolith. The physical size, number of phases and percentages of each are entered into the program as well as the size (or number) of the finite elements. The phase of individual elements will be specified via a Monte Carlo technique resulting in a random distribution of phases throughout the monolith. This for a specific IEB composition, performing a series of computer runs (with different random distributions of phases) will generate statistical data that will partly indicate the reliability of the analysis; this part of the modeling effort is only about $40 \%$ complete.

Once experimental leach data have been obtained, the data can be curve-fitted to equations and the coefficients in the equation can be used in the finite element model to generate the proper leaching rates for each of the various compositional phases. In general, any equational form could be used such as a polynomial for instance. This, however, is somewhat unsatisfactory due to the fact that the polynomial coefficients do not directly relate to any physical parameters that play a role in the leaching process. Some equations such as

$$
R=A t+B t^{1 / 2}
$$

in the Wallace-Wicks ${ }^{5}$ model where the leach rate, $\mathrm{R}$, is dependent upon a surface-reaction control coefficient, A, and a diffusion control coefficient, B, have proven to be useful, but as in this case, the formulation is entirely empirical. That is, it has not been derived from basic or underlying physical principles. A basic equation that can be derived from a few fundamental physical assumptions (see Appendix A) is

\footnotetext{
${ }^{5}$ R. M. Wallace and G. G. Wicks, "Leaching Chemistry of Defense Borosilicate Glass", Mater. Res. Soc. Symp. Proc., 15, 113-118, 1981.
} 


$$
c_{i}=c_{s}\left(1-\exp \left(-\kappa \frac{S_{a}}{V} t\right)\right)
$$

where $c_{i}$ is the concentration of species, $i$, in solution at any time $t$. The variable $c_{s}$ is the saturation concentration, $\kappa$, is the mass transfer coefficient, $S_{a}$ is the surface area of a monolith, and $\mathrm{V}$ is the volume of the liquid leachant. This equation and the others below describe the time evolution of the concentration of species, $i$, in solution for static conditions, i.e. where the volume of the leachant does not change and is not changed out or replaced. Under dynamic or flow conditions where liquid is constantly being replaced, a differential form of the equation would be used in the modeling program where $\Delta \mathrm{c}_{\mathrm{i}}=\Delta \mathrm{m}_{\mathrm{i}} / \mathrm{V}$. Concentrations in the liquid would be calculated by keeping track of mass amount, $\Delta \mathrm{m}_{\mathrm{i}}$, entering and leaving a given volume of liquid, $\mathrm{V}$.

Leach rates are also dependent upon temperature. Experimental data on the temperature dependence will be used to curve-fit to the Arrhenius equation, in which case the leach rate is proportional to

$$
\exp \left(-\frac{E_{i}}{R T}\right)
$$

where $E_{i}$ is an activation energy, $R$ is the molar gas constant, and $T$ is the temperature.

This same approach can be used to derive analytical equations for more complex situations, such as in the case of precipitation. As the concentration of a species in the liquid approaches the saturation level, there may be a tendency for the species to form solid particulate or form a film on a surface, precipitating out of solution and thus lowering the concentration, $\mathrm{c}_{\mathrm{i}}$. In the later case, precipitation onto a surface, a simplified form of a more complex equation derived by Spinosa $^{6}$ is

$$
c_{i}=c_{g}\left(\frac{k_{g}}{k_{g}+k_{x}}\right)\left(1-\exp \left(-\left(k_{g}+k_{x}\right) \frac{S_{a}}{V} t\right)\right)
$$

where $c_{g}$ is the glass saturation coefficient, $\mathrm{k}_{\mathrm{g}}$ is the glass forward dissolution rate constant and $\mathrm{k}_{\mathrm{x}}$ is and effective rate constant for growth of the precipitate film.

An equation can also be derived in the case where a depletion layer is formed on the surface of a monolith. If some species can leach out much faster than others, eventually a layer will be formed that reduces leaching of that species since it is now forced to migrate across the layer from the higher concentration areas in the interior. Diffusion across the layer will slow down the rate at which the concentration in solution can increase. Due to higher intermolecular bonding strengths in crystalline structures, we would not expect this behavior to be exhibited by the crystalline phases in IEB however, an amorphous phase like glass may

\footnotetext{
${ }^{6}$ E. D. Spinosa and J. L. Means, "Progress Report on Experimental Evaluation of a Nuclear Waste Glass Corrosion Model, Advances in Ceramics, Vol. 20, p. 531, The American Ceramic Society, 1986.
} 
be more likely to exhibit selective depletion of certain species, in particular sodium and potassium.

The reduction in the forward rate constant for that species would be expected to decrease exponentially in time according to the equation

$$
\kappa(t)=\kappa-\Delta \kappa(1-\exp (-\alpha t))
$$

where $\Delta \kappa$ is the total amount of reduction in the mass transfer coefficient and $\alpha$ is a characteristic time constant that determines how fast the reduction takes place. The equation derived (see Appendix B) using this assumption is

$$
c_{i}=c_{s}\left(1-\exp \left(-k \frac{S_{a}}{V} t+\Delta k \frac{S_{a}}{V} \frac{\alpha}{2 !} t^{2}-\Delta k \frac{S_{a}}{V} \frac{\alpha_{2}}{3 !} t^{3}\right)\right)
$$

The exponent contains the first tow non-vanishing terms of a Taylor series expansion of $\kappa(t)$. At least two terms are needed so that values for the tow constants, $\Delta \kappa$ and $\alpha$ can be determined.

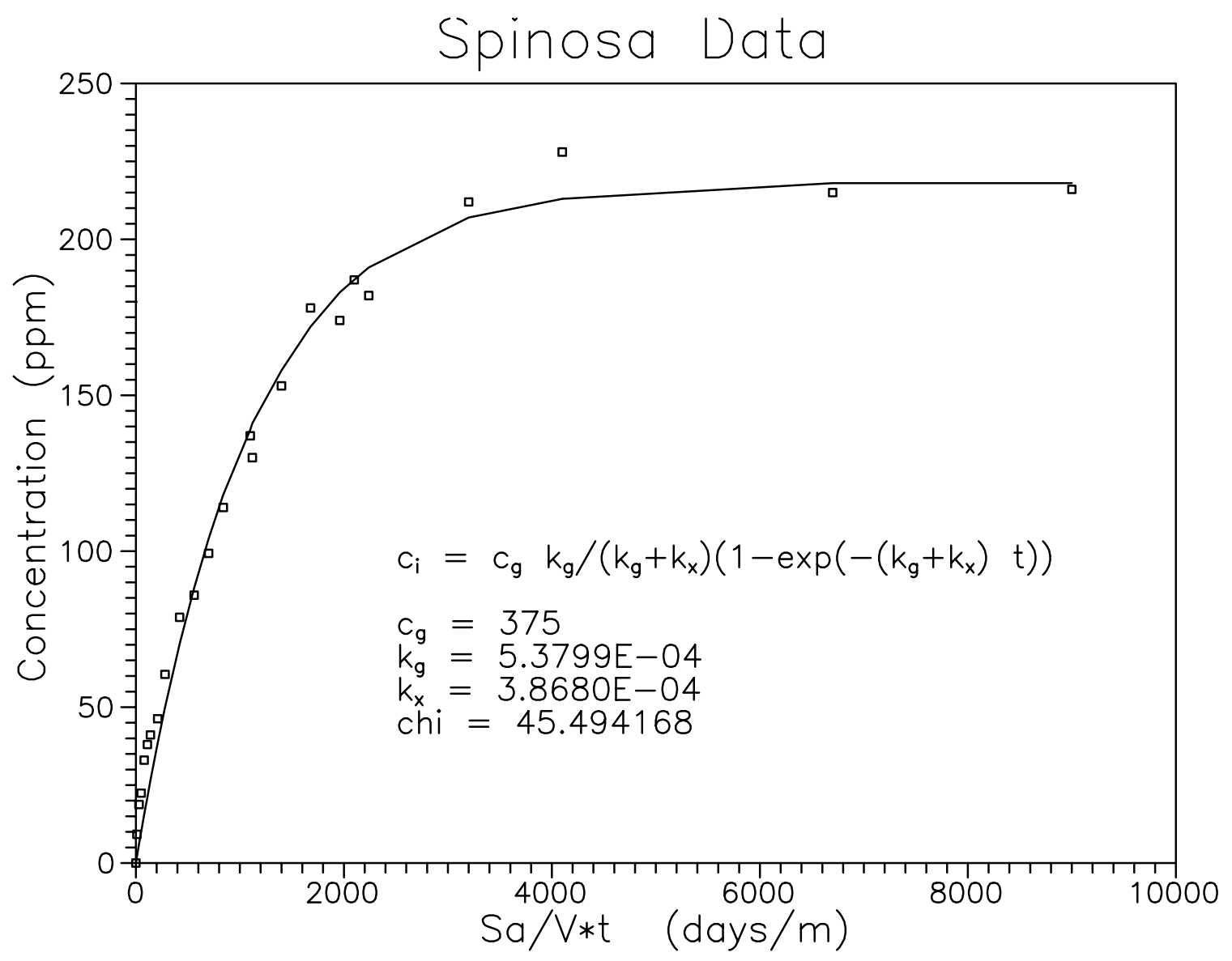

Figure 1 
Any of the three equations above may be used for curve-fitting to data, however, it must be emphasized that the underlying physical processes used in the derivation of the equations must apply. In the case of Spinosa's data, SEM/EDXS was used to confirm the precipitation of a zinc silicate phase out of solution and back onto the glass. The curve-fit for Eqn. 2 is seen below. This curve-fit can be said to be a slight improvement over a curve-fit to Eqn. 1 since the value of "chi" (the square root of the sum of the square of the differences between the data values and the curve-fit values) is lower. However, this improvement in the "goodness of fit" is only an indicator that underlying physical process inherent in Eqn. 2 is at work. Again, some type of analytical measurement must be used to confirm it.

The results of this year's modeling work is that the curve-fitting programs are complete and ready to be used. They have not been used to process any of the IEB data already obtained this year. Processing will first be done using Eqn. 1. The other equations may be used for curve-fitting also if physical evidence suggests it may be appropriate. Once this is done, the coefficients can be used in the finite element model to predict the leach behavior of any IEB composition.

\section{THERMOCHEMICAL MODELING}

The Facility for the Analysis of Chemical Thermodynamics (FACT) computational package, which includes an extensive thermochemical database, a Gibbs' free energy minimization code, and numerous solution models (including solid, liquid, molten salt and aqueous solution models) was used to predict the phase behavior of model waste form compositions. Thermodynamic calculations were completed for the three most abundant waste streams of the 30 to 35 known waste compositions. A $70 \mathrm{w} / \mathrm{o}$ waste- $30 \mathrm{w} / \mathrm{o}$ soil mixture was used to complete FACT calculations. The temperature range studied was $1600 \mathrm{~K}$ - 1900K. The chemical composition of each 70/30 waste/soil blend is in Table 2. The principle components of these three waste streams are aluminum oxide, calcium oxide, iron oxide, magnesium oxide, sodium oxide, potassium oxide, and silica. Titania and zirconia may be added to produce desirable chemical phases such as zirconolite. The fraction of zirconia in each calculation was varied from 0 to 2 w/o in order to study the effect of zirconia concentration on the formation of zirconolite. These compositions were entered into the FACT program EQUILIB to estimate the resulting chemical phases.

As a result of the calculations, the following conclusions are made: (a) The fraction of durable phases calculated (zirconolite, perovskite, apatite, etc.) increases as the melt temperature increases. (b) Zirconolite is not a significant equilibrium phase at room temperature. (c) A significant portion of the lead, sodium, copper, iron, and cadmium is in the gaseous state over the temperature range studied. As the temperature is increased, a higher fraction of these elements are found in the gaseous state. (d) A significant fraction of the chloride (and other corrosive species such as $\mathrm{SO}_{\mathrm{x}}$ ) is found in the gaseous state. It should be noted that these results were not in disagreement with experimental results.

Other valuable information that can be obtained from FACT calculations is the offgas composition resulting from high-temperature waste treatment. As most of the wastes requiring treatment contain volatile species, these can be quantified and preliminary off-gas system loading calculations can be performed. Off-gas system design was not part of the original scope of work. However, some preliminary information concerning the off-gas 
produced during the proposed waste treatment can be inferred based on the results of FACT calculations.

\begin{tabular}{|c|c|c|c|}
\hline \multicolumn{4}{|c|}{$\begin{array}{c}\text { Table } 2 \\
\text { Chemical composition of } 70 \text { w/o Transuranic Storage Area Wastes Blended with } 30 \\
\text { w/o INEEL Soil }\end{array}$} \\
\hline Component & ID-RFO-001T-N & ID-RFO-330T-N & \begin{tabular}{|l|} 
ID-RFO-480-N \\
\end{tabular} \\
\hline $\mathrm{Al}_{2} \mathrm{O}_{3}$ & 5.493 & 5.71 & 11.562 \\
\hline $\mathrm{B}_{2} \mathrm{O}_{3}$ & & & 0.084 \\
\hline $\mathrm{BaO}$ & & 0.014 & 0.0168 \\
\hline $\mathrm{CaO}$ & 7.8528 & 3.587 & 3 \\
\hline $\mathrm{CdO}$ & & 0.081 & 0.154 \\
\hline $\mathrm{CO}_{2}$ & 2.413 & 152.1 & 10.597 \\
\hline $\mathrm{Cr}_{2} \mathrm{O}_{3}$ & 0.0175 & 0.041 & 1.75 \\
\hline $\mathrm{Cl}$ & & 1.974 & \\
\hline $\mathrm{CuO}$ & 0.041 & 0.325 & 1.69 \\
\hline $\mathrm{F}$ & & 0.021 & \\
\hline $\mathrm{Ga}_{2} \mathrm{O}_{3}$ & 0.651 & & \\
\hline $\mathrm{H}$ & 0.1008 & 5.572 & 0.406 \\
\hline $\mathrm{Fe}_{2} \mathrm{O}_{3}$ & 13.346 & 3.7556 & 74.6 \\
\hline $\mathrm{PbO}$ & 0.5192 & 0.98 & 3.05 \\
\hline $\mathrm{MgO}$ & 2.675 & 1.095 & 1.62 \\
\hline $\mathrm{MnO}$ & 0.0425 & 0.14 & 0.235 \\
\hline $\mathrm{NiO}$ & & 0.066 & 0.99 \\
\hline $\mathrm{O}$ & 0.0028 & 11.858 & 0.56 \\
\hline $\mathrm{N}$ & 0.007 & 0.07 & 0.0028 \\
\hline $\mathrm{P}_{2} \mathrm{O}_{3}$ & & $7 \mathrm{E}-4$ & $3.5 \mathrm{E}-5$ \\
\hline $\mathrm{K}_{2} \mathrm{O}$ & 1.829 & 0.876 & 0.891 \\
\hline $\mathrm{SiO}_{2}$ & 30.068 & 20.6 & 21.69 \\
\hline $\mathrm{Na}_{2} \mathrm{O}$ & 4.384 & 0.583 & 0.632 \\
\hline $\mathrm{SO}_{3}$ & 0.0493 & 0.309 & 0.00727 \\
\hline $\mathrm{SnO}_{2}$ & & 0.033 & 0.172 \\
\hline $\mathrm{Ta}_{2} \mathrm{O}_{3}$ & & & 0.462 \\
\hline $\mathrm{TiO}_{2}$ & 0.2632 & 0.231 & 0.212 \\
\hline $\mathrm{WO}_{3}$ & & & 0.05297 \\
\hline $\mathrm{H}_{2} \mathrm{O}$ & 35.147 & 1.75 & 0.21 \\
\hline $\mathrm{ZnO}$ & & & 0.3503 \\
\hline $\mathrm{ZrO}_{2}$ & $0-2$ & $0-2$ & $0-2$ \\
\hline
\end{tabular}

\section{DISCUSSION}

The purpose of this project was two-pronged: (1) to develop a set of tools for predicting the phase composition of waste forms, and (2) to develop a set of tools for the prediction of the leach behavior of waste forms. The first half of the project has been completed. There is presently a state-of-the-art capability for thermochemical modeling at 
the INEEL. The selected code, EQUILIB (part of the FACT package), is a standard code that is used world-wide for chemical and metallurgical process analysis and development.

With regard to prediction of the leaching behavior of waste forms, considerable progress was made toward developing a model based on the kinetics of leaching. This approach to the challenge of predicting leaching behavior is quite sophisticated, but is expected to result in an effective tool for predicting durability of waste forms.

The notion of using predictive tools to guide experimental work is not a new one, and it is not confined to the INEEL. Recent work funded by the EPA has addressed the prediction of the leaching behavior of RCRA hazardous. ${ }^{7}$ The approach taken by Kosson in that work is less sophisticated than that taken in this project, though, because merely addressing the chemical equilibrium of these complex systems ignores the difficult problem of non-static (dynamic) leaching.

In addition, there is reason to believe that the present approach to chemical equilibrium might also be more advantageous that that taken by Kosson. The major advantage to the FACT EQUILIB approach over that of MINTEQA2 is that EQUILIB has a more extensive set of solution models. The recently developed Pitzer approach to more concentrated aqueous solutions has been incorporated into EQUILIB. This means that EQUILIB can be used to compute the equilibria of aqueous systems to a range outside the "dilute" solution limitation of the Debye-Huckel approach. In addition, it appears that the FACT package may also provide other tools (such as PREDOM and EPH) that also might be useful. Lastly, while some might disagree, standard thermochemical data that is part of a consistent data set (such as the data in the FACT database used by EQUILIB) would seem, for most cases, to be superior to the use of equilibrium constants (MINTEQA2) that are not part of a consistent data set. ${ }^{8}$

Inherent in the equilibrium approach is the assumption that the total release of material during leaching is governed by the chemical equilibria of the multi-phase, multicomponent systems that includes vapor, waste form, surrounding materials and water, all contained in a closed system. It is more likely that water entering a repository would result in a dynamic situation in which the water was flowing through, with "fresh" leachant continuously entering the system as "spent' leachant leaves. This is essentially a transpiration experiment, in which the flowing stream removes material continuously until no material is remaining (assuming, of course, that there is an infinite supply of leachant). In this situation, how "fast" material is transported becomes the important factor because this measure will determine the release rate of material.

For this reason, we have embarked on a development activity to produce a dynamic model, which will address release rates in dynamic systems as well as an equilibrium approach to address the static situation.

\footnotetext{
${ }^{7}$ A.J. Chandler, T.T. Eighmy, J. Hartlen, O. Hjelmar, D.S. Kosson, S.E. Sawell, H.A. van der Sloot and J. Vehlow, "Studies in Environmental Science 67, Municipal Solid Waste Incinerator Residues," Elsevier Science B.V., Amsterdam, The Netherlands, 607-633, 1997. ${ }^{8}$ A.J. Chandler, T.T. Eighmy, J. Hartlen, O. Hjelmar, D.S. Kosson, S.E. Sawell, H.A. van der Sloot and J. Vehlow, "Studies in Environmental Science 67, Municipal Solid Waste Incinerator Residues,” Elsevier Science B.V., Amsterdam, The Netherlands, 608, 1997
} 


\section{FUTURE STUDIES}

As was stated earlier in this report, this results of this activity have produced the groundwork upon which full-scale development of these modeling tools can be built. There are numerous deficiencies in the product produced due to the limited funding resources and time available. The areas that require additional work are presented below. In addition, Appendix C, a recently written proposal for follow-on funding, has been attached to outline the experimental activities that would support this vision.

Thermochemical Modeling- The tools needed for prediction of the phase behavior of waste forms are in place. The EQUILIB code appears to run properly, and has done a good job reproducing the phase behavior of some fairly complex systems. To demonstrate the tool, it is suggested that a set of simulated waste experiments be performed with "real " materials, wood, soil, metals, steel, etc, to see if the code adequately performs on a system that is likely to have some non-homogeneity in the starting materials. Such an approach would indicate the phases formed for which there are not data in the FACT database; these deficiencies could then be addressed.

Upon the successful completion of these tests, it is suggested that simulated radioactive waste be processed. This set of experiments would be of paramount importance because there are no thermodynamic data associated with the formation of zircon, zirconolite, calcium titanates, etc for the substitution of radionuclides into the host phases. Identification of these phases (with their substitutional constituents) would set a limit for the expected loadings of radionuclides (such as $\mathrm{Pu}$ and $\mathrm{U}$ ) into these phases. This information is important when tailoring waste from compositions.

Leach Modeling- This is where the bulk of the work in development remains to be performed. Both the MINTEQA2 and FACT EQUILIB approaches are probably adequate for equilibrium modeling, although the EQUILIB approach is superior because of the choice of aqueous solution models. In the area of dynamic modeling, however, there is the need for the extensive work to be performed.

The dynamic model is only about $40 \%$ complete. To finish the work, considerable experimental and modeling work will need to be performed. The experimental work, outlined in Appendix C, is necessary to produce the samples that will need to be studied to acquire the data necessary to build the predictive model. Leach data will need to be collected on every phase which the model will consider. This means that probably 50 suites (three temperatures and approximately 20 replicates per temperature) of leach tests need to be completed. This will require a considerable expenditure of funds and time. It is estimated that this undertaking would take 1-2 years if labor and equipment were available to perform the experiments in an expedient fashion. With the present capabilities (at the IRC), it would not be possible to complete this work in less than 5 years.

Once data are collected, they would be incorporated into the model. Subsequent to this activity, it would be necessary to perform another suite of tests on simulated radioactive wastes that would be used to demonstrate the thermochemical phase modeling code EQUILIB. This would also be a 1-2 year effort if laboratory capabilities were enhanced, and closer to 5 years under the present set of conditions. 


\section{Appendix A}

\section{Basic Mass Transfer Leaching Theory}

The process of leaching can be understood by considering a solid material surrounded by a liquid as seen in Figure 1. Mass transfer occurs across the boundary between the surface of the solid and the liquid as material dissolves into the liquid. Within a finite interval of time, the amount of mass transferred to the liquid will depend on the total surface area the solid, the amount of time over which mass transfer has taken place, and the concentration of the solute at the boundary. As the concentration increases toward the saturation level, mass transfer across the boundary will decrease and finally stop once saturation is reached. This can be put into the form of an equation ${ }^{9}$

$$
\Delta m_{i}=\kappa\left(c_{s}-c_{i}\right) S_{a} \Delta t
$$

where

$\Delta \mathrm{m}_{\mathrm{i}}-$ mass of species $\mathrm{i}$ dissolved in time $\Delta \mathrm{t}$

$\kappa$ - mass transfer coefficient, [m/day]

$c_{i}$ - concentration of species $i$ in solution at the boundary, $\left[\mathrm{g} / \mathrm{m}^{3}\right]$

$\mathrm{c}_{\mathrm{s}}$ - saturation concentration, $\left[\mathrm{g} / \mathrm{m}^{3}\right]$

$\mathrm{S}_{\mathrm{a}}$ - surface area of interface, $\left[\mathrm{m}^{2}\right]$

$\Delta \mathrm{t}$ - time interval, [days].

If we assume
concentration, $\mathrm{c}_{\mathrm{i}}$,
throughout the
the change in
be written as $\Delta \mathrm{c}_{\mathrm{i}}=$
behavior of the
function of time can
first dividing Eq. 1 by
solution and
taking the limit yields

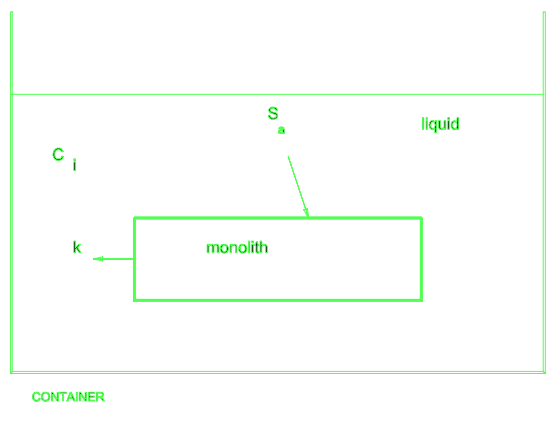

that the remains uniform leaching liquid, concentration can $\Delta \mathrm{m}_{\mathrm{i}} / \mathrm{V}$. Thus, the concentration as a be examined by the volume of the rearranging and

$$
\frac{d c_{i}}{\left(c_{s}-c_{i}\right)}=\kappa \frac{S_{a}}{V} \text { igdte 1. Dissolution(2Đ) a solid in liquid. }
$$

Eq. 2 can be integrated using the condition that at $\mathrm{t}=0, \mathrm{c}_{\mathrm{i}}=0$.

\footnotetext{
${ }^{9}$ E. L. Cussler, Diffusion: Mass Transfer in Fluid Systems, p. 215, Cambridge University
} Press, London, 1984. 


$$
\begin{aligned}
& \int_{0}^{c_{i}} \frac{d c_{i}}{\left(c_{s}-c_{i}\right)}=\kappa \frac{S_{a}}{V} \int_{0}^{t^{\prime}} d t \\
& \left.\left.\frac{1}{(-1)} \log \left|c_{s}-c_{i}\right|\right]_{0}^{c_{i}^{\prime}}=\kappa \frac{S_{a}}{V} t\right]_{0}^{t^{\prime}}
\end{aligned}
$$

Since by definition $\mathrm{c}_{\mathrm{s}}>\mathrm{c}_{\mathrm{i}}$ at all times, the absolute value signs can be dropped, and

$$
\begin{aligned}
& -\log \left(c_{s}-c_{i}\right)+\log \left(c_{s}\right)=\kappa \frac{S_{a}}{V} t \\
& \log \left(\frac{c_{s}-c_{i}}{c_{s}}\right)=-\kappa \frac{S_{a}}{V} t \\
& \frac{c_{s}-c_{i}}{c_{s}}=\exp \left(-\kappa \frac{S_{a}}{V} t\right)
\end{aligned}
$$

After rearranging, the resulting equation (Eq. 3) reveals how the concentration of species $i$ changes with time, and is plotted below in Fig. 2. As a solid dissolves, the concentration in solution increases rapidly until it approaches the saturation level.

$$
c_{i}=c_{s}\left(1-\exp \left(-\kappa \frac{S_{a}}{V} t\right)\right)
$$




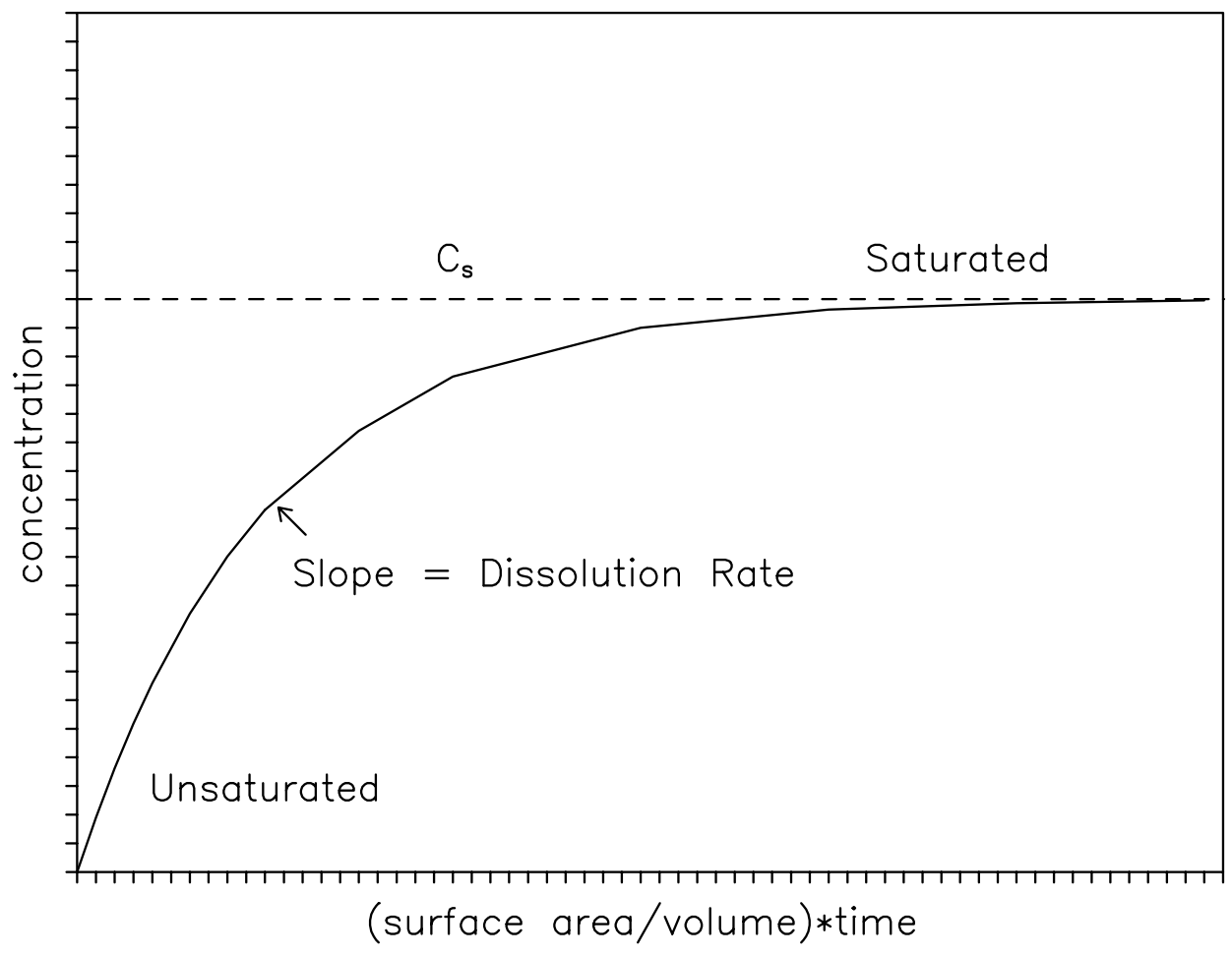

Figure 2. Typical dissolution curve as described by Eq. 3. 


\section{Appendix B}

\section{Leaching Through a Depletion Layer}

From the basic differential form of the leaching equation,

$$
\frac{d c_{i}}{\left(c_{s}-c_{i}\right)}=\kappa(t) \frac{S_{a}}{V} d t
$$

the mass transfer coefficient, $\kappa$, is now assumed to be time dependent. If a depletion layer forms as the leaching process takes place, the mass transfer coefficient would be reduced over time. This would be assumed to take place in an exponential fashion, i.e.

$$
\kappa(t)=\kappa-\Delta \kappa(1-\exp (-\alpha t))
$$

where $\Delta \kappa$ is the maximum amount of reduction in the mass transfer coefficient. The function $\kappa(\mathrm{t})$ is plotted below.

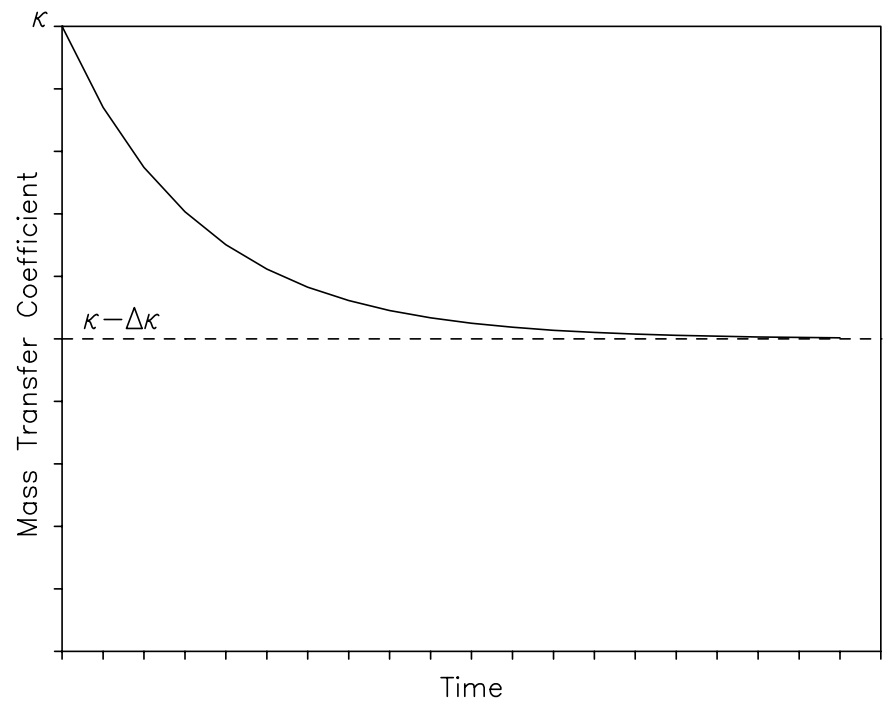

Inserting $\kappa(\mathrm{t})$ into equation (1) and expanding yields

$$
\frac{d c_{i}}{\left(c_{s}-c_{i}\right)}=\kappa \frac{S_{a}}{V} d t-\Delta \kappa \frac{S_{a}}{V} d t+\Delta \kappa \exp (-\alpha t) d t
$$

Integrating the left side of this equation yields the same result as in Appendix A and integrating the right side of the equation from 0 to $t$ yields 


$$
-\log \left(\frac{c_{s}-c_{i}}{c_{s}}\right)=\kappa \frac{S_{a}}{V} t-\Delta \kappa \frac{S_{a}}{V} t+\Delta \kappa \frac{S_{a}}{V} \frac{1}{a}(1-\exp (-\alpha t))
$$

or after taking the exponent and rearranging

$$
c_{i}=c_{s}\left(1-\exp \left(-\kappa \frac{S_{a}}{V} t+\Delta \kappa \frac{S_{a}}{V} t-\Delta \kappa \frac{S_{a}}{V} \frac{1}{a}(1-\exp (-\alpha t))\right)\right)
$$

Using a Taylor's series expansion of the exponent

$$
\exp (-\alpha t)=1-\alpha t+\frac{\alpha^{2} t^{2}}{2 !}-\frac{\alpha^{3} t^{3}}{3 !}+\ldots
$$

we find

$$
1-\exp (-\alpha t)=\alpha t-\frac{\alpha^{2} t^{2}}{2 !}+\frac{\alpha^{3} t^{3}}{3 !}-\ldots
$$

Substituting this expression back into the equation and expanding yields

$$
c_{i}=c_{s}\left(1-\exp \left(-\kappa \frac{S_{a}}{V} t+\Delta \kappa \frac{S_{a}}{V} t-\Delta \kappa \frac{S_{a}}{V} t+\Delta \kappa \frac{S_{a}}{V} \frac{\alpha}{2 !} t^{2}-\Delta \kappa \frac{S_{a}}{V} \frac{\alpha^{2}}{3 !} t^{3}+\ldots . .\right)\right)
$$

By truncating the series and since two terms cancel out, the equation becomes

$$
c_{i}=c_{s}\left(1-\exp \left(-\kappa \frac{S_{a}}{V} t+\Delta \kappa \frac{S_{a}}{V} \frac{\alpha}{2 !} t^{2}-\Delta \kappa \frac{S_{a}}{V} \frac{\alpha^{2}}{3 !} t^{3}\right)\right)
$$




\section{Proposed Work \\ Project Objectives and Significance}

Appendix C

The capability to confidently predict waste treatment product material's time dependant environmental performance over the long term is a key to achieving stakeholder acceptance of environmental remediation, waste treatment and disposal decisions. The overarching objective of the proposed work is to produce a set of scientific/engineering tools that will allow the user to use the composition of a waste stream introduced into a thermal process to predict the phase behavior and chemical durability of the final waste form. This objective will be achieved by identifying, developing and validating models that predict the phase formation of glass-ceramic composite waste forms and their durabilities (especially leach behavior) under a variety of post treatment environments (handling, storage, disposal). The development of this set of tools will support the overall goal of this proposed activity, which is to position the INEEL as the recognized leader in the area of glass-ceramic waste form development, characterization and predictive modeling for heterogeneous waste materials. In addition, the deliverables from the proposed work supports the INEEL Site Technology Coordination Group Mixed Waste need, ID-3.1.14, "Need to develop waste form standards".

High temperature thermal processes have been proposed for the treatment of a variety of radioactive and hazardous wastes, such as stored, boxed and drummed wastes, buried wastes, and HLW calcines; the waste forms produced from these processes are often glass or glass-ceramic composites. It has long been recognized that the glass-ceramic composite waste forms can be as chemically durable as glass waste forms and can have advantages over solely vitreous waste forms in other characteristics, such as waste loading and increased mechanical strength. There is presently insufficient understanding of the relationship between the thermal processes for producing these waste forms and the product performance to allow the prediction of waste form properties and chemical durability from waste stream compositions and thermal processing parameters. The deliverables for this activity are a package of computational tools for (1) predicting the products of thermal waste treatment processes (based on the input waste stream composition) and (2) predicting the chemical durability (leach behavior) of glass-ceramic thermal waste treatment products; these tools will allow the user to bridge the gap in the understanding of the relationship between waste stream composition and product performance.

The chemical equilibria of immobilization of materials in the Subsurface Disposal Area (SDA) and Transuranic Storage Area (TSA) at RWMC will be studied using readily available models, such as the FACT Gibbs free energy minimization code, EQUILIB. ${ }^{10}$ During the first year, laboratory-scale experimental studies with non-radioactive surrogates will be performed to validate the computational results; surrogate melts with "real" nonradioactive materials (wood, paper, metals, dirt, etc...) and radioactive studies are planned in the second and third years, respectively.

${ }^{10}$ C.W. Bale, A.D. Pelton and W.T. Thompson, "FACT 2.1 User's Manual," Ecole Polytechnique de Montreal/Royal Military College, Canada, July 1996 (http://www.crct.polymtl.ca). 
The durabilities of the individual phases that are present in the surrogate waste forms, the durabilities of the multi-component surrogate waste forms, and the durabilities of radioactive waste forms synthesized from RWMC TSA/SDA materials will be studied in a two-phase approach. The first phase will be the study of the release of elemental constituents during leach tests using chemical equilibrium models; the second phase will be development and application of a stochastic model to the prediction of leach behavior. The results of the modelling studies will used to validate the models.

\section{Project Description and Rationale for Approach}

As earlier stated, the overarching objective of this project is to develop a set of engineering/scientific tools for predicting the phase behavior and chemical durability of waste forms produced by thermal processing. The use of models to guide development is a standard engineering practice. Unit process models, such as ASPEN, are commonly used during for engineering process development activities. For the complex high temperature chemistry encountered during thermal processing of wastes, identifying the salient products of the process prior to performing experiments or pilot plant development can simplify and accelerate development.

The proposed project will incorporate experimental studies and modelling to attain the stated objectives. The experimental work will be used to guide and ultimately verify the modelling activities. The proposed approach is based on a wealth of activity and information available from past, related work at the INEEL and elsewhere. Thermal processes are a preferred method of immobilizing radioactive and hazardous wastes because the resulting waste forms are generally chemically and physically robust; the processes are also robust, as they accept a wide variety of feed materials and require a minimum of added reagents (as compared to aqueous chemical processes such as soil washing in which large streams of waste solutions, which must subsequently be treated, are produced), and the volume of waste, especially for the glass-ceramic waste forms, may be reduced as a result of the processing (in contrast to grouting, which generally results in a waste form of increased volume as compared to the waste stream volume).

The proposed work is novel because the resulting package of predictive codes will allow the user to select a waste stream composition and, from this composition and thermal processing parameters (temperature, cover gas, and pressure and/or volume), predict the phase behavior and chemical durability of the waste form. This approach should streamline process and waste form development activities for waste immobilization projects by allowing the user to have a scientific basis for choosing the compositions that are most likely to result in durable waste forms prior to initiating experimental work.

The proposed chemical equilibrium method of predicting the phase behavior of chemical systems is a mature scientific approach that has been used to successfully model a variety of high temperature chemistry processes, such as extractive metallurgy, slagging decontamination of radioactive metals, and alkali metal transport in silicate systems. Although other methods are occasionally used, the preferred method of computation is the Gibbs free energy minimization method. Miller and Reimann ${ }^{11}$ used this thermochemical modelling approach to predict the high temperature chemistry of immobilization of selected

${ }^{11}$ R.L. Miller and G.A. Reimann, "Thermodynamics of Gas-Metal-Slag Equilibria for Applications in In Situ and Ex Situ Vitrification Melts", report No. EGG-MS-10613, EG\&G Idaho, Idaho Falls, ID, May 1993. 
Pit 9 waste compositions; however, their code was not robust enough to consider a large number of phases and species (14 input species, 84 output species and 19 phases). In the five years since this work was published, considerable advances in PC-based thermochemical codes have been achieved. For example, the FACT EQUILIB code allows the user to input 24 species or elements and allows consideration of 500 species and phases in the free energy minimization calculation.

Molten waste mixtures of the type to be addressed in the proposed work are known to produce glass-ceramic type materials (when the chemical compositions are appropriate). Thermochemical data are available for essentially all of the pure phases that would be encountered, and solution models for glasses and slags applicable to the multi-component fractions of the waste forms are available as well. For complex phases, such as mixed metal spinels $\left(\mathrm{FeFe}_{2-\mathrm{x}} \mathrm{Cr}_{\mathrm{x}} \mathrm{O}_{4}\right)$ and zirconolite $\left(\mathrm{CaZrTi}_{2} \mathrm{O}_{7}\right)$, the entropy and free energy can be estimated by standard methods.

The more difficult portion of this modelling endeavor is modelling the chemical durability (leaching) of the product materials. To describe the results of static leach tests, the application of a chemical equilibrium model is the obvious choice. In the static leach test, the material is placed in a leachant for an extended period of time, with the limit of infinite time in the leachant being the equilibrium situation; for this situation, the equilibrium model should adequately address the "infinite time" case. This approach will also aid in identification of unexpected results, such as leaching followed by precipitation, which could lead to erroneous leach test results because the material that leached from the waste form wouldn't be present in the leachant.

An empirical model will be used in conjunction with the equilibrium model. The empirical model was developed here at the INEEL for predicting the chemical durability of multi-component waste forms. It is based on observed data for pure components and single phase glass of the types found in IEB-type waste forms. The pure component data are used to approximate the behavior of the multi-phasic mixture in this computational model, which supposes that the phases are randomly distributed throughout the waste forms, that the phases in the mixture each display the same chemical reactivity characteristics of the pure substance (which, of course, neglects all interactions between phases and any unique chemistry that occurs at the grain boundaries in the multi-component materials), and that the additive release rates for the amounts of each phase present in the multi-component material sum to the total release rate for the mixture. An eventual extension of this deterministic model would be to provide for consideration of variation and uncertainity in parameter values using a stochastic version, which would implement a Monte Carlo simulation method built around the deterministic approach. This enhanced capability will generate a statistical distribution of expected release rates for the chemical species of interest.

Lastly, mechanical durabilities of selected products will be measured in an attempt to draw correlations between the chemical and phase compositions and the mechanical durabilities of the waste forms.

FY-99 During the first year of the proposed program both modelling and experimental work is planned. The goals of the first year activities are (1) to select, develop and verify codes for the predictive work, and (2) to lay the groundwork for the surrogate experiments in the second year. Thermochemical equilibrium and leach (durability) models will be developed, analyzed and verified; the verification activities will employ samples synthesized during the experimental portion of the program. 
The most likely candidate code for the thermochemical equilibrium studies is the FACT EQUILIB code, based on the SOLGASMIX code of Eriksson, ${ }^{12}$ which utilizes a vendor-supplied database that contains thermochemical data for over 5000 species and phases. In addition, data for species/phases not in the database can be added to a "user" database and used with the vendor database. This code can be used for solids, liquids, gases and aqueous (including electrolytic) solutions. This code will be tested and verified using the results from synthesis work. This is the bulk of the thermochemical modelling work and it will be performed in conjunction with a local university using computational codes selected by LMITCO personnel.

To predict the chemical durability of waste forms, a two-phase approach will be employed. Initially, the empirical model will be applied to leach data that are already available (and to the data collected during the experimental phase of this project). This model will use a numerical computation approach and release rates for pure components/phases to compute the overall release rate for a multicomponent/multiphase material, with an initial assumption that the phases are randomly distributed throughout the material under study. Program development, testing and modification will be performed as a joint activity between LMITCO personnel and university sub-contract personnel.

Along with the empirical model which predicts release rates, a thermochemical model will be used to compute the chemical equilibrium of the waste form-water system. This approach should define a "limiting" solubility of each component of the multi-component glassceramic in the leachant and will provide further insights into other aspects of the leaching chemistry, such as identification of precipitation of leached material (which is important because release and precipitation in a static leach test would give a misleading result, based on solute concentrations in the leachant, that would be considerable different that the results from a non-static test in which the solute concentration would never build up enough to cause precipitation). Two possible codes are the FACT EQUILIB code and the MINTEQA2 code $^{13}$.

MINTEQA2 is a geochemical equilibrium speciation model for dilute aqueous solutions. Input data consist of total dissolved concentrations for the components of interest, and optionally, parameters such as $\mathrm{pH}$ or the partial pressure of one or more gases.

MINTEQA2 has an extensive thermodynamic database that is adequate for solving a broad range of problems without need for additional user-supplied equilibrium constants; in addition, the standard database can be easily modified by the user if necessary. This code has been used to address the leaching of incinerator ash, ${ }^{14}$ and its application in the proposed work would seem to be a reasonable extension of the ash studies. The equilibrium modelling

${ }^{12}$ G. Eriksson, Chemica Scripta, 8, 100-103, 1975.

${ }^{13}$ J.D. Allison, D.S. Brown and K.J. Novo-Gradac, "MINTEQA2/PRODEFA2, A Geochemical Assessment Model for Environmental Systems: Version 3.0 User's Manual," Environmental Research Laboratory, U.S. EPA, Athens, GA, 1990.

${ }^{14}$ A.J. Chandler, T.T. Eighmy, J. Hartlen, O. Hjelmar, D.S. Kosson, S.E. Sawell, H.A. van der Sloot and J. Vehlow, "Studies in Environmental Science 67, Municipal Solid Waste Incinerator Residues,” Elsevier Science B.V., Amsterdam, The Netherlands, 607-633, 1997. 
of waste form durability will be performed as a collaborative activity between LMITCO and university subcontract personnel.

Experimental activities will proceed in parallel with modelling activities. There will be three phases of synthetic work and leach testing spread over the three-year lifetime of the proposed program. The initial synthesis work will be aimed at production of single- and multi-phase materials whose leaching characteristics will be measured. This introductory synthesis work will be in the laboratory and will involve reagent-grade laboratory chemicals. The second phase of synthetic work will involve mixtures of soil and other "real" materials to be used as a non-radioactive surrogate systems for the waste streams of interest. The third phase will involve simulated TSA/SDA compositions. The second and third phases will be performed primarily in years two and three of the program.

As was previously stated, the purpose of the laboratory experiments will be to produce materials of known and reproducible chemical behavior. The reproducibility of the chemical behavior will allow these materials to be used to verify the results of the thermochemical phase behavior and leach models. Mixtures of metals, metal carbonates, and/or metal oxides will be heated in refractory crucibles in a high temperature laboratory furnace (up to 1700 Celsius). Single- and multi-phase samples will be synthesized. The single phases chosen will those which are expected to be host phases for actinides, such as zirconolite, calcium silicate and calcium titanate, as well as glasses of interest. The multicomponent samples will be based on RWMC TSA/SDA waste stream compositions. In some cases the samples will be open to air; in others, the samples may be blanketed by an inert or non-oxidizing gas. It may also be necessary to heat samples in sealed ampules or under flowing streams of oxidizing or reducing gases. The phase behavior of the products will be deduced by X-ray powder diffraction (XRD) and scanning electron microscopy (SEM).

For additional support to the modelling activities, experiments will be performed to elucidate the more esoteric chemistry of the waste forms. Sensitivity studies will be performed to see how changes in the waste stream composition, especially the alkali fraction, impact the phase behavior of the glass-ceramic products. Past work on iron-enriched basaltic (IEB) waste forms has shown that for the waste streams with large amounts of soil, the soil generally acts as a solvent and the other constituents as solutes. This means that the chemistry of the melt is dictated primarily by the soil, which buffers the effects of changes in the amounts of the minor constituents. The extent of this buffering effect, and how the physical and chemical durabilities of the resultant waste forms are impacted, needs to be understood in a more quantitative fashion so that more robust and flexible treatment processes can be developed. In addition, it is known that high alkali content can result in formation of non-crystalline (glass only) materials. This is undesirable since the glass ceramics generally have superior waste loading capabilities and physical and chemical durabilities. These experimental results will be used to validate the thermodynamic modelling technique for predicting the phase behavior of multi-component mixtures and modifications to the computational technique will be based on the results of these validation tests. The FY99 laboratory experiments will be performed by LMITCO personnel.

In addition to verification of the modelling codes with laboratory-scale results, surrogate studies with "real" non-radioactive materials will be initiated during FY99. This work will continue into FY01, with the bulk of the work being performed in FY00. Preparations for these experiments, such as identifying compositions of interest, developing 
the experimental test plan, and testing of the rammed refractory furnace will start at the end of FY99 so that experimental work can commence early in FY00. These experiments will be performed by university subcontractors.

During the first year of the proposed program, all laboratory-scale waste form materials synthesized will be leach tested by LMITCO personnel at the IRC. Numerous tests have been devised to "measure" the chemical durability of waste forms in water. Among the most commonly used leach tests in the area of radioactive waste form research are the Materials Characterization Center (MCC) and Product Consistency Test (PCT) methods, Soxlet test, steam corrosion test, and TCLP, with the MCC and PCT protocols being applied most often. In addition, the TCLP protocol is important because this is the protocol used by EPA to decide if a material is stable regarding release of hazardous constituents. The MCC and PCT are static leach tests in which the numerous replicates of the material of interest (of known mass) are each placed in a closed Teflon container containing a known mass of leachate, and held at a fixed temperature. Over a period of days $(3,7,14,28,56,91,182$, 364 for the MCC-1P method), three replicate samples are removed from the fixed temperature bath (usually a low-temperature oven), and the solutions are analyzed (ICP$\mathrm{AA} / \mathrm{AE}$ ) to determine the solutes in the leachant. The solute concentrations are used to compute the release rates for the elements of interest.

The PCT test will be used to test the chemical durability of the waste forms from this work, but TCLP tests will also be performed in some instances. This choice of PCT will allow results obtained during earlier studies to be compared to results obtained during the present work. Furthermore, the infinite time limit of this static test is the equilibrium result, which will allow a consistency check between the equilibrium leach modelling and empirical leach modelling.

The mechanical durabilities of these materials will also be measured in an attempt to draw correlations between the chemical and phase compositions and the mechanical durabilities of the waste forms. LMITCO personnel will perform this work.

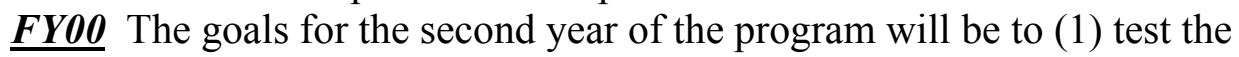
computational models on waste forms synthesized from non-radioactive "real" materials: soil, wood, metal, paper, etc..., (2) prepare for the radioactive experiments to be performed in the third year of the program, and (3) develop a stochastic model to predict leach behavior.

This second phase of synthesis activities will involve synthesis of multi-component surrogate waste forms (non-radioactive) that will be based on RWMC TSA/SDA waste compositions; once again, sensitivity studies will be performed to investigate the relationship between composition and durability. This work will be performed under a sub-contract at a local university where there is expertise and equipment available to complete the planned scope. The starting materials for these experiments will be non-radioactive materials that mimic the mixtures present in the waste streams of interest. Mixtures of soil, wood, paper, steel, sludge, etc... will be heated in a rammed-refractory induction. Heating experiments will be performed in air and under inert and/or non-oxidizing cover gases. The heating experiments will be performed by university collaborators, with input from LMITCO personnel. The phase behavior of the products will be characterized by XRD and SEM by LMITCO personnel. The results of these experiments will be used to verify the performance of the thermochemical modelling studies for "real" materials. This modelling work will be performed jointly by LMITCO and university collaborators. 
Leach testing to deduce the chemical durability of the surrogate material waste forms will be performed by LMITCO personnel at the IRC. LMITCO personnel will use these experimental results to validate the thermochemical and empirical leach modelling technique for "real" systems. The stochastic model development will take place during FY00. This activity will build upon the empirical numerical computation model developed and verified during year one of the program. LMITCO personnel will perform this work.

Lastly, mechanical testing of the surrogate waste forms will be performed in an attempt to draw correlations between the chemical and phase compositions and the mechanical durabilities of the waste forms. LMITCO personnel will perform this work.

During late FY00, preparations will be initiated for radioactive tests which will either be performed at LMITCO or ANL-W. Preparations for these experiments will entail acquisition of test materials, development of a test plan, and scheduling lab space for the melting and leach tests.

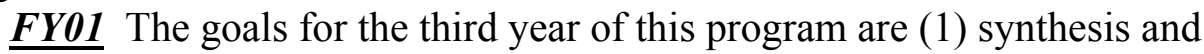
characterization of radioactive samples for modelling code validation, (2) verification of a stochastic model for leach behavior, and (3) final modifications of the predictive modelling codes. The experimental work, including leach testing, mechanical testing, and characterization, will be performed at either LMITCO or ANL-W. The model verification will be performed by LMITCO personnel with input from the university collaborators (as needed).

This third phase of the synthesis activities will involve radioactive surrogates for TSA/SDA wastes. Materials, such as wood, metals, ceramics, paper, rags, etc...will be mixed with soil, as necessary, to arrive at desirable chemical compositions identified during the first and seconds phases of the synthetic work. These mixtures will be heated under conditions identified during the first two phases of the planned program. The phase behavior of the products will be compared to the behavior predicted by the modelling results. Leach tests will be performed on the resulting materials and compared to the predictions of the leach modelling activities. These tests will provide the technical basis for validation of the stochastic leach model. Lastly, mechanical testing of the radioactive waste forms will be performed in an attempt to draw correlations between the chemical and phase compositions and the mechanical durabilities of the waste forms.

Final modifications to predictive codes will be made during the third year of the program. The codes will then be packaged, with supporting documentation, for use. This activity will be primarily performed by LMITCO personnel, with some input/assistance from the university.

The technical schedule and tasks are as follows:

\section{Schedule}

\section{YEAR 1: Laboratory Studies and Model Testing/Development}

TASK A - Identify thermochemical equilibrium codes for predicting waste form phase equilibrium. (LMITCO/university sub-contractor) (12/98)

TASK B - Identify thermochemical codes for predicting waste form chemical durability. (LMITCO/university sub-contr.) (12/98)

TASK C - Test empirical leach modelling code with published data. (LMITCO)(4/99)

TASK D - Test thermochemical leach modelling codes with published data. (LMITCO/university sub-contr.) (4/99) 
TASK E - Synthesize samples for leach behavior studies and for thermochemical equilibrium code verification. (LMITCO)(2/99)

TASK F - Perform PCT leach tests to collect data for chemical durability modelling verification. (LMITCO)(8/99)

TASK G - Validate phase equilibria modelling codes. (LMITCO/university sub-contr.)

TASK H - Validate leach modelling codes. (LMITCO/university sub-contr.) (8/99)

TASK I - Develop test plan for FY00 university surrogate tests. (LMITCO/university subcontr.) $(9 / 99)$

\section{YEAR 2: Surrogate Studies to Test/Validate Models}

TASK A - Synthesize multi-component surrogate samples using simulated waste materials (non-radioactive wood, soil, scrap metal, etc). (LMITCO/university sub-contr.) (3/00)

TASK B - Equilibrium code verification with surrogate materials. (LMITCO/university subcontr.) $(6 / 00)$

TASK C - Perform leach tests on surrogate materials. (LMITCO)(8/00)

TASK D - Develop stochastic model for leach modelling. (LMITCO)(7/00)

TASK E - Obtain materials for radioactive tests and submit test plan for management approval. (LMITCO/ANL-W)(9/00)

YEAR 3: Radioactive Studies with TSA/SDA Materials

TASK A - Use surrogate leach test results to verify stochastic leach model. (LMITCO)(1/01)

TASK B - Synthesize radioactive samples and perform leach tests. (ANL-W)(5/01)

TASK C - Use radioactive samples and leaching results to verify performance of equilibrium and leaching models. (LMITCO) $(9 / 01)$

TASK E - Final package of codes, with report, for distribution. (LMITCO)(9/01) 